source of supply of a substance fully as efficacious as, or perhaps more so than, atropine or belladonna, has for some time past attracted much attention in the colony where the plant grows, and has quite recently been brought to the notice of the Pharmaceutical Society. It is perhaps worth noting, that one of the colonial names of Duboisia myoporoides is the cork wood tree, so named from its light brown corky bark. The wood is of a light yellow colour, even grained, but soft, and used in the colony for carving. Specimens of the wood are contained in the Kew Museum.

THE additions to the Zoological Society's Gardens during the past week include an Arabian Baboon (Cynocephalus hama$d r y(a s)$ from Arabia, presented by Dr. A. P. Woodforde; two Chacma Baboons (Cynocephalus porcarius) from South Africa, presented by Capt. W. L. Coke; a Green Monkey (Cercopithecus callitrichuss) from West Africa, presented by Mr. Milward; a Great Kangaroo (Macropus giganteus), a Laughing Kingfisher (Dacelo gigantea) from Australia, presented by Lieut. Crawford Caffin, R.N.; a Short-eared Owl (Otzes brachyotus), European, presented by Mr. W. K. Stanley; a Golden-winged Parrakeet (Brotogerys chry'sopterc) from the Amazons, received in exchange ; a South American Rat Snake (Spilotes variabilis) from South America, deposited ; a Yellow-footed Rock Kangaroo (Petrogale xanthopus), born in the Gardens.

THE DETERTORATION OF OIL PATNTINGS

IL paintings are subject to varions kinds of changes, which may be considered as diseases, requiring different treatment according to their different nature. A science needs to be formed, a pathology and therapentics of oil paintings. The pathology would have to describe and explain those diseases and their progress, and to develop the methods by which a correct diagnosis could be arrived at in each individual case. The therapetutics would teach the remedies which might be applied either to cure or to alleviate the disease, or at least to stop its progress. A hygiene wotld follow, which would have to teach how to avoid pernicions influences, and which, besides, while giving precepts for the technical process of painting, wonld have to forestall those constitutional diseases which, even in cases where no noxious influences can be traced, are the cattses of decay, after a comparatively short period of existence. As medical science is above all things based on anatomy and physiology, so the exact knowledge of the structure of a picture would have to be acquired previously to any study of its disease. Unfortunately, direct investigation alone can procure no such exact knowledge; on the contrary, we are obliged to enter upon a minute historical investigation of the material as well as of the technical methods adopted by artists of different schools and different periods.

The excellent works of Cennino Cennini, Mérimée, Sir Charles Eastlake, Mrs. Merrifield, and others, have already furnished most valuable material; but still the field for investigation remains unlimited; for, in order to enable us to secure the conservation of each valtuable painting, we ought to know exactly how it was made. The artists of the present time would spare infinite trouble to the investigators of future times, if, along with their works, they would leave the account of their practice in the case of each picture. A treatment without exact knowledge of the normal condition, as well as of the nature of the disease, is, as we shall see, as dangerous for the picture as it would be in the case of living beings.

Professional restorers of pictures admit this danger in a general way; each of them, however, is convinced that he himself, by his personal knowledve, skill, and care, knows how to avoid it. The public pays too little attention to the subject, and therefore it occurred to me that it might be useful to give a short account of what we know about this question, of the changes to which oil paintings are exposed, as well as of the means either to avoid or to ctre them.

We have to consider, first, the material on which the artist has painted, that is, as far as oil painting is concerned, principally wood and canvas. ${ }^{1}$ Paper read at the Royal Institution, Friday, March I, by R. Jichreich
M. D., M.R.C.S., M.R.I.
Secondly, the priming, that is, the substance with which the surface was prepared in order to be made fit for painting.

Thirdly, the painting itself, that is, the pigments and vehicles used for $\mathrm{it}$, and the liquids that were added during the painting, the mediums, meguilp, siccatire, varnish, essential oils, \&c.

Fourthly, the coat or coats of varnish spread over the picture.

The wood on which a picture has been painted may either warp, or get chinks in it, or become worm-eaten, or even altogether rotten. Against warping, the remedy usually applied is moisture. If the panel is very thick, it is first made somewhat thinner; then the back is moistened, and the picture is left to lie on its back for twelve to twenty-four hours, after which time it will be found to have bent straight. Of course this must not be continued longer than necessary, otherwise the convex surface, instead of becoming plane, would become concave. When straight, the picture is kept so by beads which have to be adapted in a particular way, a certain degree of shifting being allowed for the expansion and contraction of the wood.

Cracks in the wood are drawn together by inserting pieces of wood of a special shape.

Sublimate solutions are employed to destroy worms.

Trifling losses of substance are replaced by cement. Small portions of rotten wood, not extending too near the painting, are cut out and replaced by wedge-shaped pieces. If, however, the greater part, or the whole substance of the panel, is rotten, the picture must be separated from it and transferred to new wood, or rather to canvas.

This was first tried by Hacquin in Paris, and was performed successfully upon many pictures, and, among others, upon one of Raphael's Madomas, in the Gallery du Louvre, and upon Sebastian del Piombo's "Resurrection of Lazarus," now in the National Gallery. The process no longer appears so very marvellous ; it is generally executed in the following way :-

First of all, the surface of the picture is pasted over with gauze and paper. After that the wood is made straight by moistening, or, if necessary, by making incisions with the saw, into which cumeiform pieces of wood are driven. By means of a tenon-saw the panel is to be sawn into little squares, which must be rremoved by a chisel, and in this way the thickness of the wood is reduced to half an inch; it is then planed until it becomes no thicker than paper, and the rest is removed by means of a knife and with the fingers. The painting being thus severed from its basis, it can be fixed on canvas, if the priming is sufficiently preserved. In the opposite case, a mixture made of chalk and glte, or something of the kind, must be put on first, and very evenly smoothed, after being dry. This done, the new canvas has to be fixed upon it by means of a mixture of glue, varnish, and turpentine, and the substance of the picture pressed tightly and evenly against it by means of warm irons.

In order to avoid deterioration, the most minute precepts have been given for preparing the panel. It has to be taken from the best oak, or nut-trees, or cedars. The wrood is to be cut into boards during winter-time, and kept till autumn before being dried; it can then be prepared only in the following spring, \&c. It would certainly be preferable to give up wood panels altogether for large pictures, and only to think of means to make the canvas stronger. For small pictures, panels offer certain advantages, and can be more easily preserved from decay.

. In the canvas we meet with the rresults of injuries or spontaneous decay. A rent may be mended by rags of linen stuck at the back of the picture. Even a hole may be filled up by pieces taken from other decayed paintings. If the picture is considerably damaged, it will be best to line it. But if the whole canvas is rotten and tattered, it will be preferable to sacrifice it by pulling off the threads one by one, after having secured the painting itself by pasting paper on the front of it. This done, the painting is transferred to another canvas in the same way as those removed from wood.

There are different modes of priming, which may be brought uncler two principal heads: the distemper and the oil priming.

I. The canvas is distempered by a mixture of chalk or plaster and paste, or glue, which may be laid on raw, unbleached can vas, or this latter may be beforehand prepared with glue or paste. Several coats of this mixture must be put on in succession, one being perfectly dry before the next can be applied. Many of the older oil paintings are painted on such ground. It has the advantage of being quicker prepared, of absorting the excess of oil, of permitting the colour to enter into the 
priming, and to dry quicker, and moreover, of containing a white absolutely innoctuous to the others.

The inconveniences, on the other hand, are: that it more easily breaks, and under the influence of humidity separates from the canvas.

2. The oil priming consists of several coats of oil colours. As each of these mist be perfectly dry before the next is laid on, and as, moreover, time must be given to the whole to dry completely before painting upon, in order to avoid the sinking in of the colours, the whole preparation is much slower than the distemper. Nevertheless it is now generally adopted.

Rey, in France, has pointed out a process which is a compromise between the two methods; he begins by distempering, and after several coats of distemper, having diried one after the other, he puts a coat of oil which, as it were, changes the distempered ground into an oil-colour ground.

With oil priming it is of importance that the principal colour be white-lead, to which are added comparatively small quantities of yellow, black, or other colours. For a whole century a school, that of Bologna, predominated in Italy, which abandoned this principle. During the second half of the seventeenth and the first half of the eighteenth century, most of the Italian masters of other schools followed its example. Probably for the purpose of obtaining more easily the desired effect of the chiaroscuro, they painted on a brownish-red priming, which consisted of bolus mixed with umber. Not one of those pictures has kept its original colouring. $\mathrm{iNot}$ only has the priming caused all the dark parts to grow much clarker, but it has destroyed, or nearly so, all the glazing, so that only those colours can be recognised which either contain white, or are glazed on white. I can show you numerous instances of this, for, on account of the extreme fertility of this school, there is little difficulty in proctring pictures of masters of that time or of their pupils.

Wood priming does not require the same elasticity as that of the canvas, which ought to be capable of being rolled. Therefore the priming of the wood shows less variations. It is generally composed of chalk or plaster, tempered with starch, paste, size, or glue, and more or less thickly laid on. In some pictures of different centuries we find, either between the wood and the priming, or between the priming and the painting, canvas, and, exceptionally, even paper.

The diseases of the priming are not of a very complicated nature. They manifest themselves principally in three different ways:-1. By cracks in the priming itself. 2. By the severance of the priming from the painting. 3. By the severance of the priming from the wood or the canvas. The third disease is by far the most frequent, especially among pictures on canvas distempered with paste. If small pieces only are scaling off or blistering, they are fixed again to the ground by letting a solntion of size pass between the detached part and the canvas, and pressing both gently together. If the deterioration extends over a considerable surface, the picture has to be lined. While this is being done, and while the gluing substance penetrates into the picture, the detached parts are pressed on again with slightly heated irons. If the whole priming threatens to come off, it will be better to take the picture entirely from the panel or canvas, and to transfer it to a new canvas.

I shall show you examples illustrating the before-mentioned points, and among them two pictures; one in oil, taken of from carvas, the other in tempera, taken off from wood. Both of them, strange to say, have escaped destruction without having been transferred to a new canvas, and without being covered with paper, as is usually done, before taking them off. They show you the painting by itself from both sides. I have, of course, used every precaution in bringing them safely over from Florence, where I happened to discover them carelessly stowed away among heaps of old pictures.

We come now to the most important part of the picture, the painting itself. We meet very often with the idea that the old masters had been in possession of colours, that is pigments, the knowledge of which has been lost, and that this accounts principally for the difference between the oil painting of the fifteenth and sixteenth centuries, on the one hand, and that of the eightecnth and nineteenth on the other. But this is a great mistake. We know perfectly well the pigments used by the old masters; we possess the same, and a considerable number of new ones, good as well as bad, in addition. In using the expression of good and bad $\mathrm{f}$ am principally thinking of thejr dura- bility. From this point of view the pigments can be placed under three headings :-

I. Those which are durable in themselves, and also agree well with the other pigments with which they have to be mixed.

2. Such as when sufficiently isolated remain unaltered; but when in contact with certain other pigments change colour, or alter the others, or produce a reciprocal modification.

3. Those which are so little durable that, even when isolated from other pigments, the mere contact of the vehicle, the air, the light, makes them in time fade, darken, or disappear alto. gether.

The old masters used, without reserve, only those belongin to the first of these categories. For those belonging to the second they imposed on themselves certain limits and precautions. Those belonging to the third they did not use at all.

That some of the modern masters have not followed these jrinciples is not owing to a lost secret, but to the fact that they disregarded those well-known principles, and even consciously acted against them. In Sir Joshua Reynolds's diary, for instance, we read that in order to produce certain tints of flesh, he mixed orpiment, carmine-lake, and blue-black altogether. Now orpiment is one of the colours of the second caterory, carmine-lalse one of the third. That is to say : orpiment, as long as it remains isolated, keeps its brilliant yellow or reddlish-orange colour ; but when mixed with white-lead it decomposes, because it consist of sulphur and arsenic, and it, moreover, blackens the whitelead, because the sulphur combines with it. Carmine-lake, even if left isolated, does not stand as an oil colour, and therefore has been superseded by madder-lake.

Unfortunately some of the most brilliant colours are perish. able to such a degree that they ought never to be used; yet, it seems to me, that just in one branch of art in which of late remarkable progress has been made, I mean landscape painting, the artists, in orcler to obtain certain effects of colour not easily to be realised, do not always resist the temptation to make use of a number of pigments, the non-durability of which is proved beyond doubt. However that may be, I think it pretty certain that the pigments in themselves play only a subordinate part in the deterioration of oil paintings, and that the principal part belongs to the vehicle with which the colours are ground, and to the liquids which are added during the painting. I hope, there. fore, you will excuse my making some elementary explanations about these liquids.

Oil and fat are bodies consisting of carbon, hydrogen, and oxygen. They may be considered as salts in which glycerine, as a basis, is combined with different acids, stearic acid, paimic acid, oleic acid. If oil is exposed to the air it changes ; certain kinds of oil remain liquid ; others become thicker and darker, and are gradually transformed into hard and opaque bodies. The drying of oils is based upon a chemical process, during which the oil oxidises by absorbing oxygen from the air, and combining a part of it with carbon to form carbonic acid, and another part with hydrogen to form water. The different oils dry with different rapidity, but this rapidity may be modified by the presence of certain substances, or by certain treatment. Linseed oil, for instance, according to the way in which it has been pressed out of the seed, contains more or less mucilaginous substances. These latter impede the drying of the oil, and have therefore to be removed by a refining process. If linseed oil in a shallow vessel is exposed to the air and light, and especially to a green light, it soon begins to dry, and is transformed first into a kind of varnish and gradually into a solid opaque substance. The drying may be quickened by boiling, and more particularly by the addition of lead, zinc, or manganese. In this way a quickdrying oil varnish may be prepared and used as a siccative. It follows that there are certain substances which impede the drying of oils, and others which facilitate it. Amongst the pigments are some which belong to this category of boclies; white-lead, zinc-white, minium, vermilion, for instance, facilitate the drying ; others, such as ivory-black, bitumen, madder-lake, will impede it. Supposing, now, we should add to each of the different pigments the same quantity of oil, the drying of it would progress at different rates. But in reality this difference is very greatly increased by the fact that the different pigments require very different quantities of oil, in order to be ground to the consistency requisite for painting.

Pettenkofer quotes the following figures, given to lim by one of the colour manufacturers:-

roo parts (weight) White-lead ," , Zinc-white $\quad . . \quad \ldots \quad$,. $\quad 1_{4}$ require 12 parts of oil 


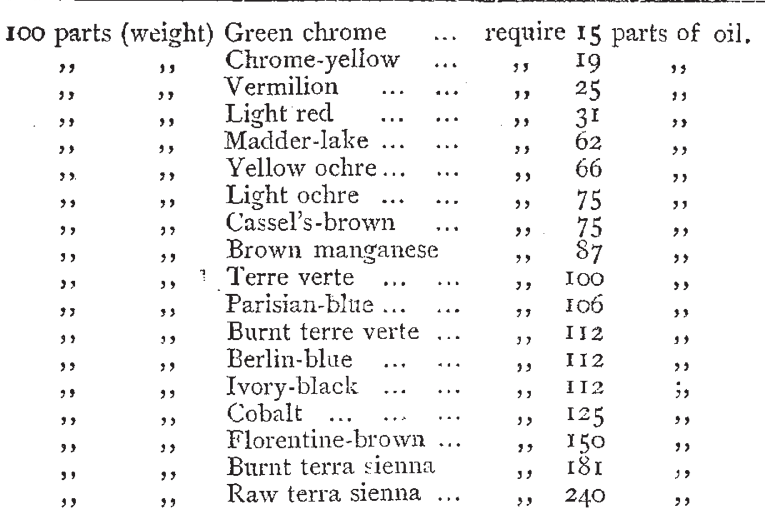

According to this table a hundred parts of the quick-drying white-lead are ground with twelve parts of oil, and on the othei hand, the slow-drying ivory-black requires one hundred and twelve parts of oil.

It is very important that artists should have an exact knowledge of these matters. But it seems to me that they are insufficiently known to most of them. All, of course, know perfectly how different the drying quality of different colours is. But that these different colours introduce into the picture so different a quantity of oil, and how large this quantity is in the colours they buy, and further, that the oil as well as the mediums or siccatives they add to dry the colours, are gradually transformed into a caoutchouc-like opaque substance, which envelops and darkens the pigments ; and moreover, that the oil undergoes - not in the beginning, but much later on when it is already completely dry-changes of volume, and so impairs the continuity of the picture-all this is not sufficiently known. Otherwise, the custom of painting with the ordinary oil colours to be bought at any colournan's, would not have been going on for nearly a humdred years in spite of all the clearly shown evil results; results due, chiefly, TO THE PRINCIPAL LNEMY OF OIL PAINTING, THAT IS TO SAY, THE OIL.

That the masters of the fifteenth and sixteenth centuries clid not use colours prepared in this way you may consider as absolutely certain; and if we hear the lost secret spoken of, and if we read that the pupils of the old nusters had to pledge themselves to keep the secret, we may be sure that it is neither the method of painting nor the pioment used for it which is concerned in that secret, but exclusively the way of preparing the colours. The preparation was a very complicated one, varying with the different pigments; and we know that the pupils passed six years, that is half of the apprenticeship, in grinding the colours for the master.

And therefore it is to this very point that everyone who wishes to study the method of the old masters must first of all direct his attention. I, too, was led by the study of this question to analyse and restore old pictures. The possibility of making such analysis we owe to the relation between the old masters and their pupils. Of course we could not dissect or chemically analyse works of Titian or Raphael. But fortunately the pupils painted with the same material and by the same method as the masters, and thousands of pictures by the pupils, well preserved or in different stages of decay, may be easily procured.

I have myself, from among a very great number of snch pictures, selected about one hundred specimens, part of which I have brought before you. As their artistic value is not, as you perceive, of the highest description, we need not feel any scruple in experimenting upon or even destroying them, if. we can thereby gain any valuable information.

( To be continued.)

\section{GAS-LIGHTING BY ELECTRICITY}

FOR some time past the street lamps in Pall Mall, Waterloo Place, and part of Regent Street, have been connected by wires, which may have led the uninitiated to think that a new method of fixing telegraphic wires was about to be adopted. This is not the case, however, for although the wires were connected with a battery, they were not intended to convey telegraphic messager, luut to experiment on a new method of lighting street lamps by means of electricity. The inventor of this method is Mr. St. George Lane Fox, who recently described his invention to the Society of Arts. Should Mr. Fox's method be adopted, the wires, instead of running from lamp to lamp above ground, will be carried along under ground, and the only thing visible would be a small piece of boxed-in mechanism just under the burner of each lamp. The experiment which was made on Saturday afternoon was not, we believe, completely successful. The magneto-electric machine and the battery which supply the current were placed in a small temporary instrumenthouse at the bottom of Waterloo Place. At the first trial the whole of the lamps in the circuit were lighted by the current, though in a second trial some of the lamps failed to respond to the current; but that this was owing to some local cause is probable from the fact that the first and last lamps in the circuit always responded to the discharge. We shall endeavour to explain the method adopted by Mr. Fox.
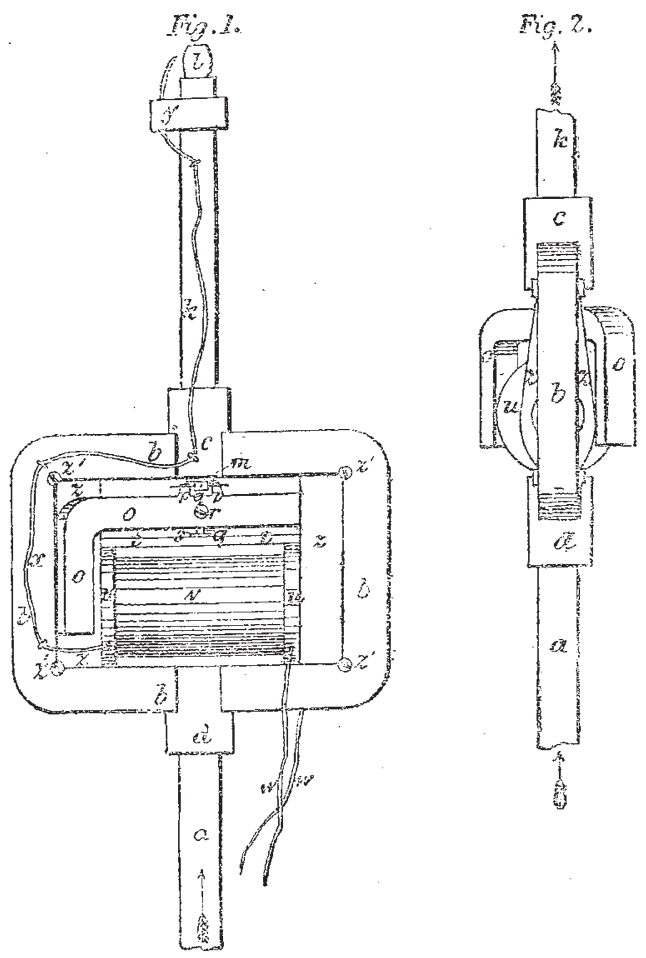

In the first place he supplies every lamp with an apparatus similar to Fig. I ; next the lamps must be connected with an insulated conductor, so that, starting from a central station, a wire would travel through each of these machines and back again to the station. Mr. Fox proposes that several of these circuits, each connecting and controlling 200 or 300 lamps, should proceed or radiate from a central station, so that from one point several thousand lamps could be operated upon almost instantaneously.

The method by which he has succeeded in producing the ignition of the gas at a considerable distance, and at numerous points, is by supplying each lamp wilh a small induction coil, so that the primary wires of each one of these induction coils forms part of the circuit, so in fact as to preserve without a break the metallic"continuity of the line. After several experiments it occurred to him that in reality the amount of work to be done in producing a number of small electric sparks was extremely minute, although at the same time requiring to be produced almost instantaneously. Now the amount of work which an electric battery will produce is dependent on the time during which action continues, and in a single instant, or say the thousandth part of a second, the actual amount of power available is naturally extremely small, and he thought that if he could by any means accumulate this power for a short tirne and then bring $i$ suddenly to bear upon the circuit, the desired result would be obtained. By means of an apparatus he succeeded in accumulating the electric current and storing it up into the condenser or 